\title{
Tandem organization and highly disparate expression of the two laccase genes Icc1 and Icc2 in the cultivated mushroom Agaricus bisporus
}

\author{
M. Smith, A. Shnyreva, D. A. Wood and C. F. Thurston \\ Author for correspondence: C. F. Thurston. Tel: +44 171333 4276. Fax: +441713334500. \\ e-mail : chris.thurston@kcl.ac.uk
}

Division of Life Sciences, King's College London, London W8 7AH, UK

\begin{abstract}
Two non-allelic laccase genes (Icc1 and Icc2) in Agaricus bisporus have been mapped to the same cosmid clone and are close together, in tandem. The intergenic region consists of 1562 bp between the stop codon of Icc1 and the start codon of Icc2. Differences between the 5 ' non-coding regions of the two genes suggest the potential for their differential regulation. By employing competitive RT-PCR and specific primer pairs that discriminate between Icc1 and Icc2, it has been shown that the level of Icc2 mRNA is approximately 300 times higher than that of Icc1 mRNA in malt extract liquid cultures; in compost cultures Icc2 mRNA is almost 7000 times more abundant than Icc1 mRNA.
\end{abstract}

Keywords: Agaricus bisporus, laccase genes, differential regulation, polyphenol oxidase

\section{INTRODUCTION}

Laccase (benzenediol:oxygen oxidoreductase, EC 1.10 .3 .2 ) is a member of the blue multi-copper family of enzymes and is produced abundantly by Agaricus bisporus, constituting $2 \%$ of mycelial protein during vegetative growth (Wood, 1980a). The enzyme is secreted into the medium and is a glycoprotein of $65 \mathrm{kDa}$ apparent molecular mass, that exists as a dimer (Wood, 1980a; Perry et al., 1993a). Laccases catalyse the oneelectron oxidation of a wide range of organic substrates, typically including mono-, di- and polyphenols, aromatic amines, methoxyphenols and ascorbate, coupled to the four-electron reduction of dioxygen to water. The occurrence of laccase is widespread amongst fungi and higher plants and the enzyme appears to have different functions in different organisms. In plants laccase has a role in the lignification of differentiating xylem tissues (Bao et al., 1993; O'Malley et al., 1993). In fungi the role of laccase is often uncertain. In plant-pathogenic fungi, such as Botrytis cinerea, laccases are one of a range of

\footnotetext{
†Present address: Department of Mycology and Algology, Moscow Lomonosov University, Moscow 1198799, Russia.

Abbreviations: ABTS, 2,2'-azino-bis(3-ethylthiazoline-6-sulphonate); DHP, dehydrogenative polymer (synthetic lignin); ME, malt extract.

The intergenic sequence between $|c c|$ and $\mid c c 2$ has been submitted to GenBank as an amendment to the genomic sequence of the laccase gene Icc1 (accession number L10664).
}

'attack' enzymes produced during the infective process (Marbach et al., 1985; Viterbo et al., 1993; Rigling \& Van Alfen, 1991, 1993). Conidiation in Aspergillus nidulans is accompanied by a laccase activity that functions in the formation of a dark-green pigment, which protects the conidia against UV radiation (Clutterbuck, 1972). More recently the involvement of laccase in lignin degradation has regained favour (Smith et al., 1997). Laccase from Trametes (Coriolus) versicolor, in the presence of mediating substrates such as ABTS, can oxidatively cleave $\mathrm{C} \alpha-\mathrm{C} \beta$ linkages of nonphenolic components of kraft pulp lignin in vitro and oxidize veratryl alcohol to veratryl aldehyde (Bourbonnais \& Paice, 1990; Bourbonnais et al., 1995). The presence of ABTS also prevented the repolymerization of the phenoxy radicals produced by the oxidation of the lignin phenolic groups. Eriksson's group have convincingly shown that laccase is essential for lignin degradation by Pycnoporus cinnabarinus, that the fungus produces a natural mediating substrate for laccase and that the laccase/mediator combination will depolymerize DHP in vitro (Eggert et al., 1996a, b, 1997). It is likely, therefore, that the very widespread occurrence of laccase in white-rot and leaf-litter-degrading fungi is (at least in part) as a component of the ligninolytic system characteristic of these fungi.

During recent years fungal laccase gene and/or cDNA sequences have been reported from a number of sources, the first of which was the ascomycete Neurospora crassa 
(Germann \& Lerch, 1986; Germann et al., 1988). Subsequently several others have been reported, with the two laccase genes $(l c c 1$ as genomic DNA and $l c c 2$ as cDNA) from Agaricus bisporus being the first to be identified as a fungal laccase gene-family (Perry et al., 1993b). More recently, four distinct laccase genes have been characterized from the plant-pathogenic fungus Rhizoctonia solani (Wahleithner et al., 1996) and five from the white-rot fungus Trametes villosa (Yaver et al., 1996; Yaver \& Golightly, 1996), and although only a single laccase gene has been isolated from the filamentous ascomycete Podospora anserina, Southern analysis and restriction mapping suggest the presence of at least three others (Fernández-Larrea \& Stahl, 1996). All these sequences encode polypeptides of about $520-600$ amino acid residues including an N-terminal secretion peptide. In sequence comparisons the overall amino acid similarity is generally not very high, but importantly they all show strict conservation in and around the single cysteine and ten histidine residues proposed as copper ligands. It is also apparent that there is some basic similarity with the other two enzymes in the large blue copper family, the plant ascorbate oxidase and the vertebrate plasma protein ceruloplasmin (Germann et al., 1988; Messerschmidt \& Huber, 1990; Messerschmidt, 1997).

Laccase gene regulation is another feature of these enzymes that differs between organisms. Some fungal laccases are inducible by substrates such as 2,5-xylidene (see Bourbonnais et al., 1995, for an example). Some are 'induced' by protein synthesis inhibitors such as cycloheximide (see for example Germann \& Lerch, 1986), but the extent to which this is solely a consequence of laccase mRNA being more stable than average is very difficult to measure; the alternative, that cycloheximide is a natural inducer, has yet to be given a plausible explanation. Many fungal laccases are apparently constitutive, but whether they are mechanistically constitutive (no sequences for modulation of transcription present) or being induced by an unidentified product of metabolism of the fungus remains unknown. The latter situation is likely to occur in A. bisporus because although laccase activity is present in a constant proportion to biomass in laboratory liquid cultures (Wood, 1980a), during the fruiting cycle in compost culture, laccase activity shows dramatic changes (Wood, 1980b).

Thus, whilst some basis for understanding the functions of laccase and its structure are developing, there is still much to be found out about the regulation of laccase synthesis, the organization of the members of gene families (where they are present) and the functions of the different members within them.

\section{METHODS}

Organism. Agaricus bisporus strain D649 was maintained on malt extract agar at $25^{\circ} \mathrm{C}$ and subcultured at monthly intervals. Cultures were grown in $(2 \%, \mathrm{w} / \mathrm{v})$ malt extract (ME) liquid medium (Boots Co.) as described previously (Perry et al., 1993a).
Harvesting and storage of $\boldsymbol{A}$. bisporus mycelium for total RNA isolation. For RNA analysis, a series of $250 \mathrm{ml}$ conical flasks containing $50 \mathrm{ml} \mathrm{ME}$ medium were each inoculated with $1 \mathrm{ml}$ homogenized mycelial suspension from a 10 -d-old ME starter-culture. Mycelium was harvested from up to ten individual flasks by filtering off onto a fine nylon mesh. The mycelium was washed with $500 \mathrm{ml}$ deionized water, 'squeezed' dry and cut into $5 \times 5 \times 5 \mathrm{~mm}$ pellets. The pellets were immediately frozen in liquid nitrogen and stored at $-70{ }^{\circ} \mathrm{C}$. A. bisporus mycelium was also grown axenically in commercial mushroom compost to the colonization stage and stored at $-70^{\circ} \mathrm{C}$ until required for RNA extraction.

Total RNA isolation. The frozen mycelial pellets, or approximately $4 \mathrm{~g}$ colonized compost, were blended to a fine powder by $2-3$ min treatment in an electric coffee bean grinder (Braun) in the presence of approximately 2 vols solid $\mathrm{CO}_{2}$ pellets. The mycelial powder and residual solid $\mathrm{CO}_{2}$ were transferred to $50 \mathrm{ml}$ polythene tubes (Falcon). After allowing the residual $\mathrm{CO}_{2}$ to sublime, but before the mycelial fragments thawed, RNA was extracted using triisopropylnaphthalene sulphonate and phenol/cresol, followed by ethanol precipitation as described previously (Leonard et al., 1981).

Removal of humic acids from compost RNA. Samples $(100 \mu \mathrm{l})$ of total RNA solution were centrifuged through $5 \mathrm{ml}$ sterile syringe barrels packed with $1.0 \mathrm{~cm}$ plastic wool and $1.5 \mathrm{~cm}$ Sephadex G-200 (Pharmacia) as descibed by Tsai \& Olson (1992).

DNA isolation. DNA from the cosmid clone LA16E2 (Sodhi, 1992) was isolated using Wizard Maxi-prep kits (Promega) for sequencing and as competitor in RT-PCR.

Sequence analysis. Sequencing by Sanger's dideoxy chaintermination method was carried out on double-stranded templates using Sequenase version 2 (USB) with specifically synthesized primers where necessary. All sequence reported was determined on both strands. Sequence data were assembled using MacVector software (IBI Pustell). Sequence comparison and alignments were performed using GCG programs (Devereux et al., 1984).

Competitive RT-PCR. All RNA preparations were treated with RQ1 DNase (Promega) to remove any contaminating DNA, according to the manufacturer's instructions, using $50 \mu$ l total RNA in a final reaction volume of $500 \mu \mathrm{l}$. The concentration of each RNA sample was determined spectrophotometrically and adjusted to $2 \mu \mathrm{g}^{-1}$ in sterile, double-deionized water. Reverse transcription and competitive RT-PCR were carried out as described by Smith (1995). Primers used were: lcc1specific primers, RP3 $\left(5^{\prime}-3^{\prime}\right.$ residues $1751-1771$ in lcc1), RP4 $\left(3^{\prime}-5^{\prime}\right.$ residues $2633-2613$ in $l c c 1$ ), RP5 (equivalent to $5^{\prime}-3^{\prime}$ residues 1751-1771 in $l c c 1$, but specific sequence of $l c c 2$ ) and RP6 (equivalent to $3^{\prime}-5^{\prime}$ residues 2343-2323 in $l c c 1$, but specific sequence of $l c c 2$; Perry et al., 1993b). Competitor DNA for both assays was serial dilutions of the genomic clone LA16E2 (which contains one copy of each gene). Analyses were carried out directly from $1.5 \%(\mathrm{w} / \mathrm{v})$ ethidium-bromidestained agarose gels using the Herolab EASY Plus enhanced analysis system running EASY Plus version 4.16 software. This system allows quantification of irradiance from individual fluorescent bands so that RNA-derived and competitor-DNA-derived band intensities can be plotted to interpolate the equivalent concentration. 


\section{RESULTS AND DISCUSSION}

\section{DNA sequence}

Evidence for the existence of two non-allelic laccase genes including the complete genomic sequence of $l c c 1$ and the close to full-length cDNA sequence of $l c c 2$ has been reported previously (Perry et al., 1993b). Further restriction mapping and Southern analysis of cosmid clones from a library (Sodhi, 1992) of Agaricus bisporus

(a)

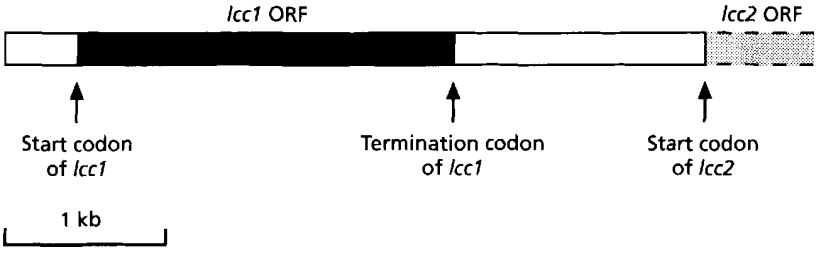

(b)

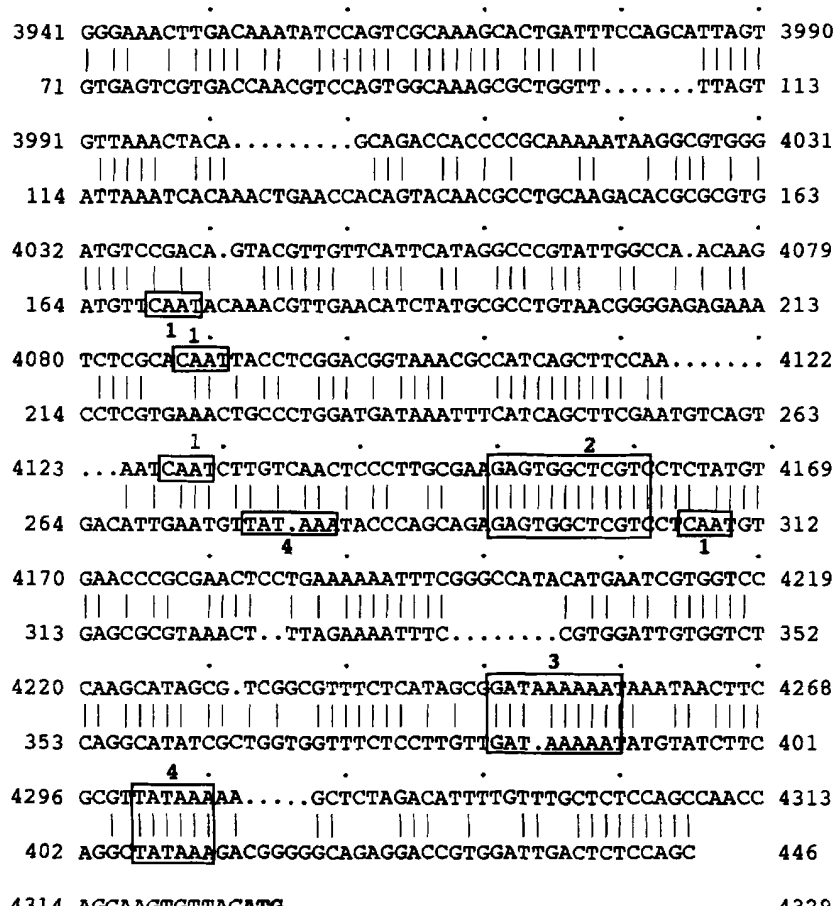

4314 AGCAAGTGTTACATE

Fig. 1. (a) Arrangement of the $/ \mathrm{cc} 1$ and $/ \mathrm{cc} 2$ genes. The distance between the two ORFs is $1562 \mathrm{bp}$. Only the beginning of the Icc2 ORF is shown, as this sequence has largely been analysed as CDNA. (b) Comparison (BESTFIT) of the lac2-proximal part of the intergenic sequence (upper sequence) with the $5^{\prime}$ non-coding region of $/ c c 1$ (lower sequence). The coding sequence of $/ \mathrm{cc} 1$ starts at residue 460 (not shown) and the coding sequence for ICC2 starts at residue 4327 . Putative regulatory sequences are identified as follows. 1, CAAT boxes. Eight further CAAT motifs (not shown) are present in the intergenic sequence at residues 3877-3880 and positions further upstream from the start of Icc2, but not at equivalent positions upstream of $|\mathrm{cc}|$, in the region that has so far been sequenced. 2, Heat-shock response element binding site. 3, Residues identical to the $5^{\prime}$ region of the laccase gene of Coriolus hirsutus and the yeast GAL4 binding site. 4, TATA boxes.
C-54-carb-8 (a fungicide-resistant mutant; Loftus et al., 1988) had shown that both laccase sequences were present in the cosmid clone LA16E2, approximately $2 \mathrm{~kb}$ apart. PCR with all possible combinations of primers for extension out of the ends of both genes gave a consistent product only with the combination $5^{\prime}-3^{\prime}$ primer close to the $3^{\prime}$ end of $l c c 1$ combined with $3^{\prime}-5^{\prime}$ primer close to the $5^{\prime}$ end of $l c c 2$, indicating a tandem arrangement with $l c c 1$ upstream of $\left(5^{\prime}\right.$ to) $l c c 2$ (results not shown). Although the nucleotide sequences of $l c c 1$ and $l c c 2$ are largely the same $(8.6 \%$ difference in the coding regions) there are small regions of divergence, particularly within the $5^{\prime}$ coding region of the genes, which permitted the design of sequence-specific primers. This enabled the nucleotide sequence of the intergenic region to be sequenced directly from the clone LA16E2. The $3^{\prime}-5^{\prime}$ sequencing primer complementary to the $5^{\prime}$ region of $l c c 2$ had a 4 base mismatch at its $3^{\prime}$ end compared to $l c c 1$ sequence. Because very little $3^{\prime}$ noncoding sequence from $l c c 2$ was available for comparison, however, the initial $5^{\prime}-3^{\prime}$ sequencing primer from the $3^{\prime}$ non-coding region of $l c c 1$ (complementary to residues 2874-2893 in $(c c 1$ ) was designed beyond the stop codon (residues 2762-2764), but with 115 bp of known lcc1 sequence downstream for comparison to ensure correct lcc1-specific priming. Thereafter, specific, sequential primers were designed to obtain the full sequence in both strands. The organization of the two laccase genes, with 1562 bp separating the stop codon of $l c c 1$ and the start codon of $l c c 2$ is shown in Fig. 1(a).

Multiplicity of laccase genes differing only slightly in sequence is apparently not uncommon in fungi. This is sometimes simply due to allelic differences as found in Neurospora crassa (Germann et al., 1988) and the laccase genes (PO1 and PO2) of Coriolus hirsutus (Kojima et al., 1990). In contrast, of the four laccase genes isolated from Rhizoctonia solani, three are closely linked in tandem (and the fourth is an allele of one of the others; Wahleithner et al., 1996). Five non-allelic laccase genes have been characterized from the white-rot basidiomycete Trametes villosa (Yaver et al., 1996; Yaver \& Golightly, 1996). Two genes (lcc1 and $l c c 2$ ) correspond to the purifed laccase protein-forms 1 and 3 respectively. Under the conditions tested, no RNA species representing $l c c 3,4$ and 5 could be detected. The organization of these genes in relation to one another has not been established. Considering Agaricus bisporus genes other than laccase, there is presently only one report of two non-allelic homologous genes. Harmsen et al. (1992) have shown the presence of a (pseudo)gene $\left(G P D^{\mathrm{Ag} 1}\right)$ similar to the glyceraldehyde-3-phosphate dehydrogenase gene $\left(G P D^{\mathrm{Ag} 2}\right)$. These two sequences are closely linked and while the deduced amino acid sequence of GPD ${ }^{\mathrm{Ag} 1}$ conserves many important structural features associated with GPD ${ }^{\mathrm{Ag} 2}$, transcripts of this gene have not been found in either fruit bodies or mycelium.

The alignment of the $3^{\prime}$ region of the intergenic sequence (the $5^{\prime}$ non-coding region of $l c c 2$ ) with the $5^{\prime}$ non-coding region of $l c c 1$ is shown in Fig. 1(b). The sequences show 
(a)

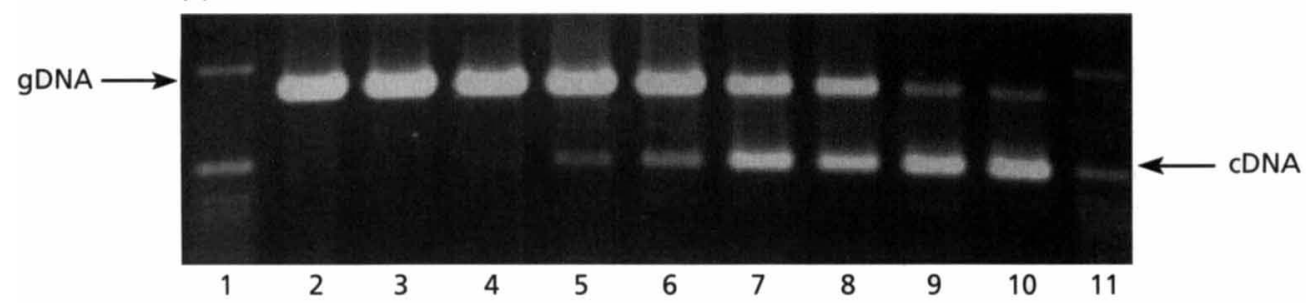

(b)

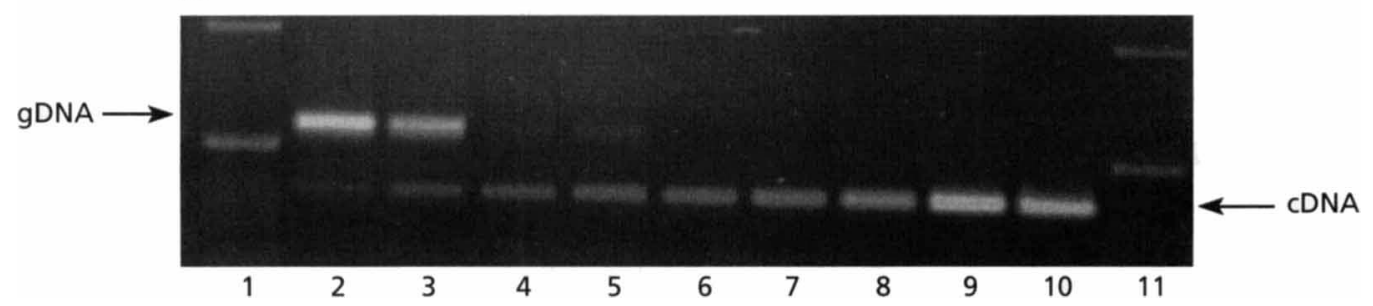

Fig. 2. Competitive RT-PCR analysis of mRNA from the laccase genes $/ c c 1$ (a) and $l e c 2$ (b) of $A$. bisporus. Total RNA was extracted from mycelium grown in ME liquid medium. Reverse transcriptase reactions were carried out with $2 \mu \mathrm{g}$ total RNA. Individual PCRs were 'spiked' with serial dilutions of the competitor genomic clone LA16E2. In each case $30 \%$ of the PCR mixture was resolved on a $1 \%$ (ethidium-bromide-containing) agarose gel. In both (a) and (b) lanes 1 and 11 contained $1 \mathrm{~kb}$ ladder (BRL). The competitive genomic fragments ( $881 \mathrm{bp}$ in a, $592 \mathrm{bp}$ in b) and CDNA-derived fragments ( $500 \mathrm{bp}$ in a, $386 \mathrm{bp}$ in b) are indicated with arrows as gDNA and CDNA, respectively. In both (a) and (b), dilutions for the competitor genomic clone contained (lanes $2-10$, respectively): $1.6 \times 10^{-6}, 0.8 \times 10^{-6}, 1.6 \times 10^{-7}, 0.8 \times 10^{-7}, 1.6 \times 10^{-8}$, $0.8 \times 10^{-8}, 1.6 \times 10^{-9}, 0.8 \times 10^{-9}, 1.6 \times 10^{-10} \mathrm{~mol}$.

significant similarity. Allowing gaps as shown in Fig. 1 (b), $61 \%$ of residues are identical. A number of unique and common, putative, transcription-factor-binding sites have been identified. Of the two putative 'TATA' boxes and a single 'CAAT' box previously identified in lcc1, only the second TATA box is found in both genes. Possible 'CAAT' boxes unique to $l c c 2$ are numerous, with examples at residues $3877-3880,4087-4090$ and 4126-4129, 392, 182 and 147 bp from the common TATA box (the closer of which are shown in Fig. 1b). The cel1 (Raguz et al., 1992), cel3 (Chow et al., 1994) and $G P D^{\mathrm{Ag} 2}$ (Harmsen et al., 1992) genes from $A$. bisporus contain similar 'TATA' sequence elements that generally conform to the asymmetric consensus sequence TAT(A/T)AA (Breathnach \& Chambon, 1981), as do all the fungal laccase genes sequenced to date. However, the cel1 gene (Raguz et al., 1992) and laccase 1 gene from Aspergillus nidulans (Aramayo \& Timberlake, 1990) have the symmetrical sequence TATA and the GPD ${ }^{\mathrm{Ag} 2}$ gene has TACAAAAA. The inverted repeat and regions of similarity with Neurospora crassa and the La France disease-associated double-stranded M1 RNA virus previously reported for the $5^{\prime}$ region of $l c c 1$ (Perry et al., 1993b; Smith, 1995) are not present in the intergenic sequence.

The 'core' heat-shock elements (HSE) present in both non-coding regions (feature 2 in Fig. 1b) typically form part of contiguous arrays of variable numbers of the 6 bp sequence NGANNN arranged in alternating orientations (Sorger, 1991). It is thought that a minimum of two units are required for high-affinity heat-shock binding and such arrays are present in both sequences. HSE involvement in control of ligninolytic enzymes has been extensively studied with respect to manganese peroxidases of Phanerochaete chrysosporium (Gold \& Alic, 1993; Li et al., 1995). There may be other similarities between manganese peroxidase and laccase gene expression, as both may be controlled by metal response elements (MREs). MRE consensus sequences are found in the promoter regions of $m n p 1$ and $m n p 2$ of P. chrysosporium (Gold \& Alic, 1993) and at residues 4298-4304 close to the start of $l c c 2$.

A short sequence also found in the $5^{\prime}$ region of the laccase gene from Coriolus hirsutus is present (Fig. 1b), that also matches the binding sequence for the yeast Gal4 transcription initiator (Selleck \& Majors, 1987). Differences in the sequences for putative regulatory sites suggest a potential for differential regulation between lcc1 and lcc2. This is comparable to the many lignin peroxidase and manganese peroxidase genes of Phanerochaete chrysosporium (Gold \& Alic, 1993). For all the sequence motifs discussed above, however, it will remain uncertain as to whether any of them are functional transcription factor recognition sites until a reliable transformation system is developed for A. bisporus.

A potential polyadenylation signal sequence, conforming to the higher eukaryotic consensus AATAAA (Proudfoot \& Brownlee, 1976) is present in the intergenic sequence (residues 3394-3399). This, together with the $1563 \mathrm{bp}$ of coding sequence, is in agreement with the previous estimate for the size of laccase mRNA at $2 \cdot 3 \pm 0 \cdot 15 \mathrm{~kb}$ (Perry et al., 1993b). The function of this 
Table 1. Quantification of $/ c c 1$ and $/ c c 2$ mRNA by competitive RT-PCR

\begin{tabular}{|lccc|}
\hline & & \multicolumn{2}{c|}{ Specific mRNA (mol per $\mu$ g total RNA)* } \\
\cline { 2 - 4 } & $\begin{array}{l}\text { Source of } \\
\text { mycelium... }\end{array}$ & ME medium & Compost culture \\
\hline$l c c 1$ & & $1 \cdot 0 \pm 0 \cdot 1 \times 10^{-17}$ & $4 \cdot 5 \times 10^{-19}$ \\
$l c c 2$ & $3 \cdot 0 \pm 0 \cdot 4 \times 10^{-15}$ & $3 \cdot 0 \times 10^{-15}$ \\
Ratio $l c c 2 / l c c 1$ & & 300 & $\sim 7000$ \\
\hline
\end{tabular}

*Values for RNA from ME culture are the mean \pm SD of four independent samples; those from compost culture are the mean of duplicate assays of a single sample.

sequence remains speculative, as no cDNA clones for laccase that include (part of) the poly(A)-tail have so far been isolated.

\section{Laccase mRNA levels}

The results of the discriminatory $l c c 1-l c c 2$ competitive RT-PCR from 10-d-old ME liquid culture and colonization-stage compost mycelium are shown in Fig. 2 and Table 1 . The highest value obtained for laccase mRNA (lcc2) was $3 \times 10^{-15} \mathrm{~mol}$ per $\mu \mathrm{g}$ total RNA and was the same for both ME-grown and compost-grown mycelium. It is clear that $l c c 2 \mathrm{mRNA}$ was very much more abundant than $l c c 1$ mRNA in both culture conditions. In ME medium, levels of $l c c 2$ mRNA were nearly 300 times higher than those of $l c c 1$ mRNA; in compost, $l c c 2$ mRNA was almost 7000 times more abundant than $l c c 1$. This result is paradoxical in the sense that the species which varies in concentration, and which is therefore apparently under some form of regulation, is very much the minor component and consequently cannot have any significant direct effect on overall laccase expression. This suggests that the two laccase gene products have different functions and/or that the two genes are controlled by different regulatory circuits, that respond to different conditions. The latter proposition would suppose that there are conditions (which we have yet to find) where $l c c 1$ expression is relatively high.

Differential expression in laccase gene-families has recently been reported from two other fungi. In the basidiomycete Trametes villosa, lcc1 mRNA could be induced approximately 17 -fold by the addition of 2,5 xylidine to the culture. This corresponded to a 20 -fold increase in enzyme activity; however, $l c c 2$ mRNA could not be induced and was present at a constitutive level which was approximately half that of the uninduced lcc1 mRNA (Yaver et al., 1996a, b). The plant-pathogenic fungus Rhizoctonia solani has a family of four laccase genes, three of them located within a $12 \mathrm{~kb}$ fragment of the genome. These are present at low constitutive levels and are further suppressed by addition of $p$-anisidine to the cultures. The mRNA for the fourth laccase is present at higher basal levels and its transcription is increased in response to $p$-anisidine (Wahleithner et al., 1996).
There are now several examples of systems in which mRNA degradation may contribute significantly to the control of expression of fungal genes (see for example Sachs, 1993). In Agaricus bisporus, the cel1 and cel3 genes may be controlled in part by mRNA degradation (Yagüe et al., 1994; Chow et al., 1994). For both cel1 and cel3 expression, although no mRNA accumulated under repressing conditions (as measured by Northern analysis), de novo transcripts were produced in nuclear runon experiments, at comparable levels to control messages that did accumulate on Northern blots. This suggests that, at least under repressing conditions, the cel mRNAs are subject to rapid turnover.

Further mechanistic detail of the control of expression of genes for secreted enzymes of A. bisporus will not be easily acquired, as simple correlations between rate of enzyme accumulation, mRNA level and rate of transcription do not obtain in laboratory liquid culture (Yagüe et al., 1994; Chow et al., 1994). At the same time, the methods described here have enabled us to examine individual mRNA levels in solid (compost) culture. Expression of genes in compost mycelium during the whole fruiting cycle will be described elsewhere.

\section{ACKNOWLEDGEMENTS}

Advice and assistance on bioinformatics from Dr Phil Cunningham are most gratefully acknowledged. This work was supported by the Biotechnology and Biological Sciences Research Council of the UK. A.S. acknowledges support from the European Environmental Research Organization.

\section{REFERENCES}

Aramayo, O. R. \& Timberlake, W. E. (1990). Sequence and molecular structure of the Aspergillus nidulans $y A$ (laccase 1) gene. Nucleic Acids Res 18, 3415.

Bao, W., O'Malley, D. M., Whetten, R. \& Sederoff, R. R. (1993). A laccase associated with lignification in loblolly pine xylem. Science 260, 672-674.

Bourbonnais, R. \& Paice, M. G. (1990). Oxidation of nonphenolic substrates. An expanded role for laccase in lignin biodegradation. FEBS Lett 267, 99-102.

Bourbonnais, R., Paice, M. G., Reid, I. D., Lanthier, P. \& Yaguchi, M. (1995). Lignin oxidation by laccase isozymes from Trametes 
versicolor and role of the mediator 2,2'-azinobis(3-ethylbenzthiazoline-6-sulfonate) in Kraft lignin depolymerisation. Appl Environ Microbiol 61, 1876-1880.

Breathnach, R. \& Chambon, P. (1981). Organisation and expression of eukaryotic split genes coding for proteins. Annu Rev Biochem 50, 349-383.

Chow, C.-M., Yagüe, E., Raguz, S., Wood, D. A. \& Thurston, C. F. (1994). The cel3 gene of Agaricus bisporus codes for a modular cellulase and is transcriptionally regulated by the carbon source. Appl Environ Microbiol 60, 2779-2785.

Clutterbuck, A. J. (1972). Absence of laccase from yellow spored mutants of Aspergillus nidulans. J Gen Microbiol 70, 423-435.

Devereux, J., Haeberli, P. \& Smithies, O. (1984). A comprehensive set of sequence analysis programs for the VAX. Nucleic Acids Res 12, 387-395.

Eggert, C., Temp, U., Dean, J. F. D. \& Eriksson, K.-E. L. (1996a). A fungal metabolite mediates degradation of non-phenolic lignin structures and synthetic lignin by laccase. FEBS Lett 391, 144-148.

Eggert, C., Temp, U. \& Eriksson, K.-E. L. (1996b). The ligninolytic system of the white rot fungus Pycnoporus cinnabarinus: purification and characterisation of the laccase. Appl Environ Microbiol 62, 1151-1158.

Eggert, C., Temp, U. \& Eriksson, K.-E. L. (1997). Laccase is essential for lignin degradation by the white-rot fungus Pycnoporus cinnabarinus. FEBS Lett 407, 89-92.

Fernández-Larrea, J. \& Stahl, U. (1996). Isolation and characterisation of a laccase gene from Podospora anserina. Mol Gen Genet 252, 539-551.

Germann, U. A. \& Lerch, K. (1986). Isolation and partial nucleotide sequence of the laccase gene from Neurospora crassa: amino acid sequence homology of the protein to human ceruloplasmin. Proc Natl Acad Sci USA 82, 8854-8858.

Germann, U. A., Muller, G., Hunziker, P. E. \& Lerch, K. (1988). Characterisation of two allelic forms of Neurospora crassa laccase: amino- and carboxyl-terminal processing of a precursor. $J$ Biol Chem 263, 885-896.

Gold, M. H. \& Alic, M. (1993). Molecular biology of the lignindegrading basidiomycete Phanerochaete chrysosporium. Microbiol Rev 57, 605-622.

Harmsen, M. C., Schuren, F. H. J., Moukha, S. M., Carin, M. Z., Punt, P. J. \& Wessels, J. G. H. (1992). Sequence analysis of the glyceraldehyde-3-phosphate dehydrogenase genes from the basidiomycetes Schizophyllum commune, Phanerochaete chrysosporium and Agaricus bisporus. Curr Genet 22, 447-454.

Kojima, Y. M., Tsukuda, Y., Kawai, Y., Tsukamoto, A., Sugiura, J., Sakaino, M. \& Kita, Y. (1990). Cloning, sequence analysis, and expression of lignolytic phenoloxidase genes of the white-rot basidiomycete Coriolus hirsutus. J Biol Chem 265, 15224-15230.

Leonard, J. C., Dunham, S. M. \& Thurston, C. F. (1981). Isolation of RNA from Chlorella fusca var. vacuolata. New Phytol 87, 39-51.

Li, D., Alic, M., Brown, J. A. \& Gold, M. H. (1995). Regulation of manganese peroxidase gene transcription by hydrogen peroxide, chemical stress and molecular oxygen. Appl Environ Microbiol 61, 341-345.

Loftus, M. G., Moore, D. \& Elliott, T. J. (1988). DNA polymorphisms in commercial and wild strains of the cultivated mushroom, Agaricus bisporus. Theor Appl Genet 76, 712-718.

Marbach, I., Harel, E. \& Mayer, A. M. (1985). Pectin, a second inducer for laccase production by Botrytis cinerea. Phytochemistry 24, 2559-2561.
Messerschmidt, A. (1997). Multi-copper Oxidases. Singapore: World Scientific Publishing Co.

Messerschmidt, A. \& Huber, R. (1990). The blue oxidases, ascorbate oxidase, laccase and ceruloplasmin, modelling and structural relationships. Eur J Biochem 187, 341-352.

O'Malley, D. M., Whetten, R., Bao, W., Chen, C.-L. \& Sederoff, R. (1993). The role of laccase in lignification. Plant J 4, 751-757.

Perry, C. R., Matcham, S. E., Wood, D. A. \& Thurston, C. F. (1993a). The structure of laccase protein and its synthesis by the commercial mushroom Agaricus bisporus. J Gen Microbiol 139, 171-178.

Perry, C. R., Smith, M., Britnell, C., Wood, D. A. \& Thurston, C. F. (1993b). Identification of two laccase genes in the cultivated mushroom Agaricus bisporus. J Gen Microbiol 139, 1209-1218.

Proudfoot, N. J. \& Brownlee, G. G. (1996). 3' non-coding region sequences in eukaryotic messenger RNA. Nature 263, 211-214.

Raguz, S., Yagüe, E., Wood, D. A. \& Thurston, C. F. (1992). Isolation and characterisation of a cellulose-growth-specific gene from Agaricus bisporus. Gene 119, 183-190.

Rigling, D. \& van Alfen, N. K. (1991). Regulation of laccase biosynthesis in the plant-pathogenic fungus Cryphonectria parasitica by double-stranded RNA. J Bacteriol 173, 8000-8003.

Rigling, D. \& van Alfen, N. K. (1993). Extra- and intracellular laccases of the chestnut blight fungus Cryphonectria parasitica. Appl Environ Microbiol 59, 3634-3639.

Sachs, A. B. (1993). Messenger RNA degradation in eukaryotes. Cell 74, 413-421.

Selleck, S. B. \& Majors, J. (1987). Photofootprinting in vivo detects transcription-dependent changes in yeast TATA boxes. Nature 325, 173-177.

Smith, M. (1995). Molecular analysis of the laccase genes from Agaricus bisporus. PhD thesis, University of London.

Smith, M., Thurston, C. F. \& Wood, D. A. (1997). Fungal laccases: role in delignification and possible industrial applications. In Multi-copper Oxidases, pp. 201-224. Edited by A. Messerschmidt. Singapore: World Scientific Publishing Co.

Sodhi, H. S. (1992). Enzyme mutants of Coprinus bilanatus and recombinant DNA technology for strain improvement in Agaricus bisporus. $\mathrm{PhD}$ thesis, University of London.

Sorger, P. K. (1991). Heat shock factor and the heat shock response. Cell 65, 363-366.

Tsai, Y.-L. \& Olson, B. H. (1992). Rapid method for separation of bacterial DNA from humic substances in sediments for polymerase chain reaction. Appl Environ Microbiol 58, 2292-2295.

Viterbo, A., Yagen, B. \& Mayer, A. M. (1993). Cucurbitacins, 'attack' enzymes and laccase in Botrytis cinerea. Phytochemistry $32,61-65$.

Wahleithner, J. A, Xu, F., Brown, K. M., Brown, S. H., Golightly, E. J., Halkier, T., Kauppinen, S. \& Pederson, A. (1996). The identification and characterisation of four laccases from the plant pathogenic fungus Rhizoctonia solani. Curr Genet 29, 395-403.

Wood, D. A. (1980a). Production, purification and properties of extracellular laccase of Agaricus bisporus. J Gen Microbiol 117, 327-338.

Wood, D. A. (1980b). Inactivation of extracellular laccase during fruiting of Agaricus bisporus. J Gen Microbiol 117, 339-345.

Yagüe, E., Wood, D. A. \& Thurston, C. F. (1994). Regulation of transcription of the cel1 gene in Agaricus bisporus. Mol Microbiol $12,41-47$.

Yaver, D. S., Feng, X., Golightly, E. J., Brown, K. M., Brown, S. H., 
Rey, M. W., Schneider, P., Halkier, T., Mondorf, K. \& Dalbøge, H.

(1996). The purification, characterisation, molecular cloning and expression of two laccase genes from the white-rot basidiomycete Trametes pinsitus. Appl Environ Microbiol 62, 834-841.

Yaver, D. S. \& Golightly, E. J. (1996). Cloning and characterisation of three laccase genes from the white-rot basidiomycete Trametes villosa: genomic organisation of the laccase gene family. Gene $181,95-102$.

Received 4 August 1997; revised 5 November 1997; accepted 2 December 1997. 